took a median of 30 minutes to arrive at the patient's home and 20 minutes to reach the hospital. When the same variables were analysed in the patients subsequently confirmed to have definite or probable acute myocardial infarction it was found that the decision time was shorter if relatives were with the patient at the onset of symptoms.

The interval between admission to hospital and administration of streptokinase in those given the drug was the longest single delay (median 102 minutes). No factors were identified that significantly influenced the time of administration of streptokinase.

Thus most elderly patients reach hospital in time to benefit from thrombolytic treatment but many elderly patients are not admitted to coronary care units. Not only must attention be given to shortening the time to administration of thrombolytic treatment but elderly patients with suspected acute myocardial infarction should have the potential benefit of specialised coronary care.

S ARINO A BAYER

University Department of Geriatric Medicine, Cardiff Royal Infirmary,

Cardiff CF2 ISZ

1 Elder AT, Fox KAA. Thrombolytic treatment for elderly patients. BMF 1992;305:846-7. (10 October.)

2 Birkhead JS. Time delays in provision of thrombolytic treatment in six district hospitals. BM7 1992;305:445-9. (22 August.)

3 Dudley NJ, Burns E. The influence of age on policies for admission and thrombolysis in coronary units in the United Kingdom. Age Ageing 1992;21:95-8.

EDITOR,-Andrew T Elder and Keith A A Fox highlight the issue of age and thrombolytic treatment in myocardial infarction. ${ }^{1}$ The medicine for the elderly unit at Burnley operates an age related policy, admitting all patients aged 71 and over presenting as medical emergencies. We have only limited access to the coronary care unit. We started using thrombolytic treatment over four years ago and participated in the third international study of infarct survival. This further exacerbated problems of access to the coronary care unit. Attempts to give this treatment in a busy general ward caused inordinate pressure on the nursing and medical staff, particularly at weekends and nights.

An audit of myocardial infarction in January and February 1991 showed that of the 41 patients diagnosed as having myocardial infarction, only five received thrombolytic treatment. In 10 the diagnosis could not be made on admission and became apparent when electrocardiography was repeated the next day. Nineteen patients had clear contraindications. In seven patients no reason was apparent for their not receiving thrombolysis. Lack of suitable monitoring and pressure on medical and nursing time were identified as reasons for the poor results. We therefore implemented a vigorous policy of training junior medical staff and started to plan a high dependency unit in our department to provide monitoring facilities and trained nursing staff to supervise the administration of thrombolytic treatment as well as other critically ill patients.

A repeat audit in January and February this year showed considerable improvement. Fifteen patients out of 43 received thrombolytic treatment, but the number of missed early diagnoses was still large because of lack of monitoring facilities. We opened a four bedded high dependency unit in June this year. A preliminary analysis of the first 100 admissions to the unit showed that 44 patients were diagnosed as having myocardial infarction. In 12 patients myocardial infarction was not immediately evident on admission but became apparent during early monitoring. Twenty nine patients were given thrombolytic treatment. All patients who were eligible received the treatment; we have no upper age limit. The rate of complications has been no higher than expected.
In elderly patients with myocardial infarction the diagnosis is often unclear on presentation, and monitoring these patients has enabled us to establish the diagnosis and to give thrombolytic treatment if appropriate. We are undertaking a formal study of outcomes, including length of stay and function. The development of a high dependency unit devoted exclusively to elderly people has enabled us to give our patients the proved benefit of this treatment.

V P HAJELA

S K SINGH

Medicine for the Elderly Unit,

Burnley Health Care NHS Trust,

Burnley General Hospital

Burnley BB10 2PQ

1 Elder A, Fox KA. Thrombolytic treatment for elderly patients. $B M F$ 1992;305:846-7. (10 October.)

\section{Communicating with patients}

EDITOR,-Information for patients, always a neglected topic, has now become one of patients' rights embodied in the patient's charter. Since 1983 Brighton Health Authority has been committed to producing good quality literature as part of a consumer affairs initiative and has won national recognition for its publications for patients.

We looked at the written material given to patients from wards, outpatient clinics, community clinics, health centres, and other departments in the health district. A doctor and a nonmedical researcher formed a joint opinion on the visual appearance, content, factual accuracy, style, and presentation of each item. They awarded an overall grade to each item according to whether it was acceptable or needed revision. They then did a readability test on a random sample.

The volume of material available was surprising, though the response from the mental health sector was disappointing. Subjects covered included information for patients before a procedure and after a procedure, information on health promotion topics, and general information. We divided the publications into the following categories: in house (produced by the department concerned, 356), professional organisation (produced outside the health authority and NHS but including the Health Education Authority, 247), pharmaceutical companies (192), self help groups or charities (30), the district health promotion department (22), and miscellaneous (91)

Of the in house literature, 246 items were considered to be unacceptable and 10 to be in urgent need of attention. Two hundred and seventeen publications had been photocopied, of which 171 were of a poor standard, usually because photocopies had been taken of photocopies. Fifty three items of in house material lacked a department or subject heading, logo, or date so that the information had no context. Seventy one items were considered to be unfriendly, instructions were brusque and dictatorial, almost to the point of being rude-a failing accentuated when the text was in note form, especially if abbreviations were used and there was no introduction. Twenty eight publications were considered to be too technical because they used medical terms and jargon unnecessarily or withou explanation.

A particularly poor example was a leaflet for women going home after a hysterectomy. The front cover featured an inappropriate, tasteless cartoon of a chicken wearing an apron and a chef's hat stirring a pot, with the title "Your recipe for home." There was no department heading, logo, or date. The first page had a list of contents with no page numbers; it was followed by a description of what the patient was to expect postoperatively, nformation for patients should:

- have the department heading, the date, and the health authority logo

- have an introduction and a list of contents with page numbers if appropriate

- have all text in sentences, without abbreviations, jargon, or complicated medical terms

- be professionally printed or at least produced on a word processor

- have short paragraphs with double spacing between them. Numbering of paragraphs may be helpful

- be photocopied from the original material

- be assessed by as many medical and non-medical people as possible before reproduction

illustrated with anatomical diagrams. The explanation then continued in question and answer form: "Although my womb has been removed, my ovaries have been left behind. As I have not reached the 'change of left' [sic], do I still need to use contracaptive [sic]. The simple anwer [sic] is no. The womb as [sic] an incubator for the devoloping [sic] baby, so without it pregnancy is impossible."

A random sample of leaflets was selected and tested for readability by the "gobbledegook" test. This is a rough measure of readability for adult readers based on the principle that long sentences and polysyllabic words are harder to understand. Unfortunately, words such as diabetes, alcohol, and cholesterol were often found in the leaflets; and many other factors that affect readabilitysuch as sentence structure, print size, and the educational background of the reader-are not taken into account by readability tests. Of the 524 leaflets selected, 96 were not suitable for the test because they consisted of diet sheets or lists of addresses. Twenty five had a score rating them as "very hard to read," on a level with the Times and the Guardian, and therefore unsuitable for the general reader.

As a result of the study all departments were sent a code of good practice (box) and told that the public relations officer was available for advice. New leaflets will soon replace the 10 leaflets considered to be in most urgent need of redesign. In house literature is valuable, but departments must follow guidelines and districts must set aside realistic budgets for producing good quality patient information. This will then complement the clinical care that patients receive.

J BENNETT P BRIDGER

Brighton Health Authority,

Brighton General Hospital,

Brighton BN2 3EW

\section{Outcome of breech delivery at term}

EDITOR,-The reply of J G Thorpe-Beeston and colleagues $^{1}$ to the criticisms of their paper on the risks of term breech delivery ${ }^{2}$ emphasises the importance of antenatal counselling. While accepting that it is difficult to propose a policy decision on the basis of their study, they advocate the use of their perinatal mortality figures when advising women about vaginal breech delivery. In their original paper they state that many women would find a figure "approaching 1\%" disturbing and would opt for caesarean section. In their letter they suggest that women may find a risk presented as "no more than $1 \%$ " acceptable. This is a good illustration how the same statistic can be used to influence a patient's decision in either direction, and that a hidden statistic, the doctor's attitude, may be more important than the quoted figure 
itself. Surely doctors would also have to inform the woman that this perinatal mortality rate would, by their own data, still mean a risk increased 28 -fold over that in delivery by caesarean section, and I doubt whether many women would find a risk presented in this way very reassuring.

But it is doubtful whether the authors are justified to use their figures for antenatal counselling purposes at all. It has to be recognised, for medicolegal as well as counselling purposes, that women for a "trial of vaginal delivery" and those who actually had a vaginal delivery represent overlapping but essentially different populations Some women who deliver vaginally were no intended for a trial, and often were not even known to have a breech presentation, and many women who were planned to have a "trial" do not end up being delivered vaginally.

Antenatal counselling must emphasise the increased risk for intrapartum intervention, but the onus of proof for advising a routine intervention such as elective caesarean section must lie with the advocates of such a policy. Unless solid data to the contrary emerge, I will continue to counsel women with a mature fetus presenting by the breech that, given proper antenatal assessment and selection, and with modern methods of obstetric management, there is no evidence of any increase in perinatal mortality associated with a trial of vaginal delivery.

Perinatal Research and Monitoring Unit,

Department of Obstetrics and Gynaecology,

University Hospital, Queen's Medical Centre,

Nottingham $\mathrm{NG} 72 \mathrm{UH}$

Thorpe-Beeston JG, Banfield PJ, Saunders NJStG. Outcome of breech delivery at term. BMf 1992;305:746-7. (26 September.) Thorpe-Beeston JG, Banfield PJ, Saunders NJStG. Outcome of breech delivery at term. BMf 1992;305:1092. (31 October.)

\section{Serotonin, gastric emptying, and dyspepsia}

EDITOR,-In their paper on the role of central serotonin receptors in non-ulcer dyspepsia $\mathrm{A}$ Chua and colleagues claim that the prolactin response to buspirone provides an index of the function of central serotonin-1A receptors. Unfortunately for the authors, there is compelling evidence that this is not true and that antagonism of dopamineD2 receptors is the main mechanism by which buspirone stimulates secretion of prolactin.

Firstly, buspirone binds with only slightly less affinity to dopamine-D2 receptors than to serotonin-1 receptors.' Secondly, in an isolated rat pituitary model buspirone was shown to antagonise the inhibitory effects of dopamine on release of prolactin. ${ }^{3}$ Thirdly, in human studies comparison of buspirone with two related serotinin-1A agonists, gepirone and ipsapirone, shows that only buspirone potently stimulates secretion of prolactin whereas they all share similar effects on growth hormone, cortisol, and body temperature. ${ }^{4}$ This difference is probably due to gepirone and ipsapirone lacking significant affinity for dopamine-D2 receptors.

Fourthly, in an antagonist study using pindolol, a $\beta$ blocker with serotonin-1A antagonist properties, we found that the growth hormone and hypothermic responses to buspirone were abolished whereas there was only a small, nonsignificant reduction in the size of the prolactin response..$^{5}$ Our negative finding has subsequently been replicated by another group. ${ }^{\circ}$ The study that Chua and colleagues cite in their support of their contention was of only two subjects ${ }^{i}$ and can be dismissed. Blockade of this response by metergoline and methysergide does occur but is probably due to their dopamine-D2 agonist properties, ${ }^{8}$ and, consistent with this, metergoline antagonises the prolactin response to haloperidol in normal volunteers. ${ }^{9}$ Taken together, these lines of evidence mean that the authors' confident statement that secretion of prolactin stimulated by buspirone is a "good measure of the sensitivity of central serotonin-1A receptors" is not supported by the facts, which indicate dopamine-D2 mediation.

In conclusion, I remain sceptical about this and similar studies using the prolactin response to buspirone as an index of the function of serotonin-1A receptors, particularly when evidence indicates that the growth hormone or adrenocorticotrophic hormone response would be a more valid index.

\section{Department of Psychiatry,}

IAN ANDERSON

University of Manchester,

Manchester Royal Infirmary,

Manchester M13 9WL

1 Chua A, Keating J, Hamilton D, Keeling PWN, Dinan TG Central serotonin receptors and delayed gastric emptying in non-ulcer dyspepsia. BMF 1992;305:280-2. (1 August.)

Gammans RE, Mayol RF, Labudde JA. Metabolism and disposition of buspirone. Am $\mathcal{F}$ Med 1986;80(suppl 3B):41-51.

Meltzer HY, Simonovic M, Fang VS, Gudelsky GA. Effect of buspirone on rat plasma prolactin levels and striatal dopamine buspirone on rat plasma prolactin levels and

4 Cowen PJ, Anderson IM, Grahame-Smith DG. Neuroendocrine effects of azapirones. F Clin Psychopharmacol 1990;10(suppl 3):215-55

5 Anderson IM, Cowen PJ. Effect of pindolol on endocrine and temperature responses to buspirone in healthy volunteers. Psychopharmacology 1992;106:428-32.

6 Meltzer HY. Effect of buspirone on prolactin secretion is not mediated by $5-\mathrm{HT}_{1 \mathrm{~A}}$ receptor stimulation. Arch Gen Psychiatry 1992;49:163.

Coccaro BF, Gabriel S, Mahon T, Macaluso J, Siever LJ Preliminary evidence of a serotonin (5-HT-1-like) componen to the prolactin response to buspirone challenge in humans. Arch Gen Psychiatry 1990;47:594.

8 Krulich I McCann SM, Mayfield MA. On the mode of the prolactin release inhibiting action of the serotonin receptor prolactin release inhibiting action of the serotonin receptor Endocrinologv 1981;108:1115-24

9 Ellis PM, Gartside SE, Ware CJ, Campling GM, Cowen PJ. Does metergoline selectively attenuate 5-HT mediated prolactin release? Psychopharmacology 1991;105:129-31.

Authors' REPLy,-Ian Anderson suggests that the prolactin response to stimulation with buspirone is mediated via dopamine-D2 receptors. Serum prolactin concentration can be increased by 5-hydroxytryptophan, direct acting serotonin agonists, and serotonin releasers, while serotonin receptor blockers lower prolactin concentrations. ${ }^{12}$ Investigators have also shown that the serotoninergic stimulation of prolactin release is not by inhibition of dopaminergic activity.

Buspirone is an agonist at presynaptic and postsynaptic 5-hydroxytryptamine type-1A (serotonin-1A) receptors. Its activity at presynaptic dopamine receptors, however, is not considered characteristic of the azaspirones. ${ }^{3-5}$ When taken orally buspirone and gepirone, another azaspirone with a highly selective ligand for brain serotonin-1A receptors, increase plasma prolactin concentrations. ${ }^{0-x}$ The fact that plasma prolactin concentrations were not affected by ipsapirone could be explained by its associated serotonin-1 receptor antagonist property. ${ }^{9}$ The prolactin response to buspirone seems to be at serotonin receptors, as suggested by the buspirone-metergoline study, and more specifically at the serotonin-1-like receptors (buspirone-pindolol study). The different results observed in prolactin suppression with pindolol (mixed agonist-antagonist properties at the serotonin-1A receptor) in Cocarro et als and Meltzer et al's studies ${ }^{710}$ are due to the administration of different doses of D1-pindolol (higher doses tend to display serotonin-1A receptor agonist effects). Effects of buspirone on central dopaminergic receptors remain unresolved with conflicting agonist " and antagonist properties.

Studies in our unit with bromocriptine (a dopamine agonist) in patients with non-ulcer dyspepsia did not show any difference from findings in healthy controls (unpublished). Furthermore patients with non-ulcer dyspepsia treated with sertraline and fluoxetine (selective serotonin reuptake inhibitors) show a precipitation of their symptoms initially, further supporting the theory of hypersensitive serotoninergic receptors (this study is continuing)

In reply to Malcolm H Duncan's letter, ${ }^{12}$ all the patients investigated in our study had dyspeptic symptoms of more than three months' duration with no concomitant symptoms or illness. They were all within $10 \%$ of their ideal body weight. As mentioned in our paper, they constitute up to $35 \%$ of our patients with functional dyspepsia. All the above patients underwent a full psychiatric assessment by a consultant psychiatrist, including completion of the comprehensive psychopathological rating scale. ${ }^{13}$ None of the patients studied had any evidence of psychiatric disorders.

Only one patient with non-ulcer dyspepsia had a prolactin response that overlapped that in the controls, though it was in the upper range of normal. One patient did have a particularly high response, but assessment of the prolactin response with geometric means showed a similar significant difference between patients and controls. Furthermore, later studies with other patients have shown similarly high responders. T G DINAN

Departments of Gastroenterology and Psychiatry,

Trinity College Medical School,

St James's Hospital,

Dublin,

Republic of Ireland

1 Takahara J, Yamauchi J, Niimi M, Kageyama J, Aoki Y, Fujino $\mathrm{K}$, et al. Mechanism of prolactin release by 5-hydroxytryptophan. Life Sci 1981;29:1463-6.

2 Quattrone A, Tedeschi G, Aguglia U, Scopacasa F, Direnzo GF, Annunziato L. Prolactin secretion in man: a useful tool to evaluate the activity of drugs on central 5-hydroxytryptaminergic neurons. Studies with fenfluramine. $\mathrm{Br} f \mathrm{Clin}$ Pharmacol 1983;16:471-5.

3 Coop CF, McNaughton N. Buspirone affects hippocampa rhythmical slow activity through serotonin $1 \mathrm{~A}$ rather than dopamine D2 receptors. Neuroscience 1991;40:169-74.

4 Lader M. Can buspirone induce rebound, dependence or abuse? Br f Psychiatry 1991;159(suppl 12):45-51.

5 Louillot A, Le Moal M, Simon H. Presynaptic control of dopamine metabolism in the nucleus accumbens: lack of effect of buspirone as demonstrated using in vivo voltametry. Life Sci 1987;40:2017-24.

6 Dinan TG, Barry S, Yatham LN, Mobayed M, O'Hanlon M. The reproducibility of the prolactin response to buspirone: relationship to the menstrual cycle. Int Clin Psychopharmacol 1990;5:119-23.

7 Coccaro E, Gabriel S, Mahon T, Macaluso J, Siever LJ Preliminary evidence of a serotonin (5-HT-1-like) componen to the prolactin response to buspirone challenge in humans. Arch Gen Psychiatry 1990;47:594-5.

8 Cowen PJ, Anderson IM, Graham-Smith DG. Neuroendocrin effects of azaspirone. $\mathcal{F}$ Clin Psychopharmacol 1990;10:21-5S

9 Goodwin GW, De Souza JR, Green AR. The effects of a 5-HT receptor ligand isapirone (TV Q 7821) on 5-HT synthesis and behavioural effects on 5-HT agonist in mice and rats. Psychopharmacology 1986;89:382-7.

10 Meltzer HY, Lee HS, Nash JF. Effect of buspirone on prolactin secretion is not mediated by 5 -HT-1 a receptor stimulation. Arch Gen Psychiatry 1992;49:163-4.

11 Fletcher PJ, Davies M. The involvement of 5-hydroxytryptaminergic and dopaminergic mechanisms in the eating induced by buspirone, gepirone and ipsapirone. $B r$ Pharmacol 1990;99:519-25.

12 Duncan MH. Serotonin, gastric emptying, and dyspepsia. $B M \gamma$ 1992;305:585-6. (5 September.)

3 Asberg M, Pernig C, Schaling D, Sedvall G. The CPRS development and applications of a psychiatric rating scale. Acta Psychiatr Scand 1978;271(suppl):5-27.

\section{Hepatitis B vaccination}

EDITOR,-There is a developing paradox in relation to hepatitis $\mathbf{B}$ vaccination of health care workers.

Firstly, we have the advice that, at least in adults, the immune status in relation to hepatitis B does not depend on the level of circulating antibodies-that the long term protection resides in the memory cells in the immune system.' We are told that no health care worker who has initially responded to the vaccine has developed hepatitis $B$ infection or carrier status regardless of the reduc- 